\title{
Assessment of eco-toxic effects of commonly used water disinfectant on zebrafish (Danio rerio) swimming behaviour and recovery responses: an early-warning biomarker approach
}

\author{
Zongming Ren ${ }^{1} \cdot$ Yaxin $\mathrm{Yu}^{1} \cdot$ Mathan Ramesh ${ }^{2} \cdot{\text { Bin } \mathrm{Li}^{1} \cdot \text { Rama-Krishnan Poopal }}^{1}$
}

Received: 21 July 2021 / Accepted: 21 December 2021 / Published online: 31 January 2022

(C) The Author(s), under exclusive licence to Springer-Verlag GmbH Germany, part of Springer Nature 2021

\begin{abstract}
Eco-toxicity profiles for commonly used disinfectants were lacking. Available traditional toxicity techniques have some limitations (assessments and ethical issues). Behaviour toxicology is a promising research area towards early warning and non-invasive approaches. We studied the potential eco-toxic effects of sodium hypochlorite $(\mathrm{NaOCl})$ on the swimming behaviour of zebrafish. Zebrafish were exposed to different concentrations (Treatment I, Treatment II, Treatment III, and Treatment IV) of $\mathrm{NaOCl}$ for $360 \mathrm{~h}$. Recovery study (144 h) was conducted for $\mathrm{NaOCl}$ treatment groups. The swimming behaviour of zebrafish was quantified efficiently using an online monitoring system (OMS). OMS dataset was processed for determination of behavioural differences by MATLAB and SPSS. Compared to the control group, the swimming strength of zebrafish under $\mathrm{NaOCl}$ treatments declined significantly $(p<0.001)$. Avoidance behaviour has occurred on zebrafish under $\mathrm{NaOCl}$ exposure periods. Furthermore, $\mathrm{NaOCl}$ toxicity also adjusted circadian rhythms on zebrafish. Zebrafish swimming strength was significantly $(p<0.001)$ improved under-recovery periods. Moreover, normal diurnal patterns have occurred. $\mathrm{NaOCl}$ could cause behavioural abnormalities in non-target organisms. Continuous exposure to common disinfectants could cause external and internal stress on non-target organisms, resulting in behavioural changes and circadian rhythm adjustments. Continuous changes in behavioural and circadian rhythms might reduce organisms' fitness and adaptation capacity. This study highlights (1) the importance of computer-based toxicity assessments, and (2) swimming behaviour is an early warning biomarker for eco-toxicity studies.
\end{abstract}

Keywords Disinfectant $\cdot$ Environmental pollution $\cdot$ Aquatic concern $\cdot$ Stress indicator $\cdot$ Real-time assessment

Responsible Editor: Bruno Nunes

Zongming Ren and Yaxin Yu contributed equally to this paper.

\section{Highlights}

- Sodium hypochlorite $(\mathrm{NaOCl})$ is potentially a behavioural disruptor.

- Swimming behaviour could be reliable non-invasive biomarkers for eco-toxicity studies.

- A concentration-dependent toxicity was observed on zebrafish under $\mathrm{NaOCl}$ treatments.

- Avoidance behaviour resulted on zebrafish under prolonged exposure to $\mathrm{NaOCl}$.

- Recovery responses are an auxiliary study for eco-toxicity studies.

Bin Li

605083058@qq.com

Rama-Krishnan Poopal poopalramakrishanan@ymail.com

Extended author information available on the last page of the article

\section{Introduction}

Water demand and pollution lead to the treatment and reuse of water resources (Senthil Rathi et al. 2021). Failure of water treatment systems in inactivating pathogens has resulted in outbreaks of many waterborne diseases and illnesses. Disinfectants are the best option for eradicating microbes in water treatment systems and other fields (aquaculture, agriculture, domestic purposes, and health care centres) (Holm et al. 2019; Yun et al. 2020; Choi et al. 2021; Huang et al. 2021). Different kinds of disinfectants were commercially available (totally 131 household products) for use (Goh et al. 2021). Chlorine is predominantly disinfectant because of its significant antimicrobial activity and least expensive advantages (Dastagiri Reddy and Elias 2021). Sodium hypochlorite ( $\mathrm{NaOCl})$ is a mostly used chlorine-based disinfectant; since the seventeenth century, it has been capable of destroying pathogens (including persistent 
pathogens) more efficiently (Ujimine et al. 2017). Thus, most household bleach contains $\mathrm{NaOCl}$ (up to $9 \%$ ) as the active ingredient (CDC-https://cfpub.epa.gov/giwiz/disin fectants/index.cfm). NaOCl-based products are recognised as essential germicides (US-EPA 1967). They are used in different (domestic, industrial, aquaculture, agriculture, veterinary practices, scientific, and biomedical) applications (dwell time: $30 \mathrm{~s}$, pathogens: bacteria and viruses) (Emmanuel et al. 2004; Tudela et al. 2019; Duerschner et al. 2020). The EPA recently recommended $\mathrm{NaOCl}$ (EPA itemised: 72 products, formulation type: dilutable, wipe, ready to use, Viking, electrostatic spray; surface type: hard nonporous, food contact post rinse required) as the active ingredient to inactive SARS-CoV-2 (US-EPA 2021). The WHO also recommended $\mathrm{NaOCl}$ as biocides at $0.1 \%$ and $0.5 \%$ for general environmental and blood spill disinfections, respectively, for SARS-CoV (WHO 2020). Overuse of disinfectants (e.g., $\mathrm{NaOCl}$ ) resulted in the mortality of 17 different free-living species in Chongqing, China (Nabi et al. 2020). Environmental factors govern the decomposition process of $\mathrm{NaOCl}$, decompose slower with air, and the process is accelerated under direct light conditions. $\mathrm{NaOCl}$ has been categorised under Class-I toxic substance by US-EPA due to its developmental effects on biota (as mentioned in Elia et al. 2006). The concern is that approximately $80 \%$ of wastewater (including aquaculture wastewater) is rereleased to environmental compartments without proper treatment (Xie et al. 2019; Deere et al. 2020). Global use of disinfectants is also escalating (up to 0.78 billion during 2020) after the pandemic (Subpiramaniyam 2021). Generally, a high concentration $(1000 \mathrm{ppm})$ of $\mathrm{NaOCl}$ is required to neutralise pathogens in the contaminated zones (bathroom and toilet) (Rim 2021). Hence, it is essential to measure disinfectant performance and the potential impacts on non-target organisms to ensure their safety and sustainability (Macedo et al. 2020; WHO 2020).

Increasing the biological effects of waterborne contaminants has led the scientific community to develop biomarkers using biological models (Makaras et al. 2018; Falcao et al. 2019). Biological monitoring methods provide information on waterborne contaminants' potential impacts on ecological risk assessment (Makaras et al. 2020) . Zebrafish is the most recommended model for various (behavioural, neuro-, and ecotoxicology) aquatic biological monitoring studies (Hong and Zha 2019; Loring et al. 2020; de Oliveria et al. 2021). Available traditional biological endpoints have some limitations: toxicity tests conducted at high concentrations; no early-warning biomarkers are focused (Magalhaes et al. 2007; Hong and Zha 2019). Behavioural activity is the primary response of organisms to reveal the initiation of changes in physiological and ecological processes. Thus, an organism's behavioural activity can be recognised as valid biomarkers to assess the water quality of an aquatic ecosystem and the toxicity of waterborne contaminants (Xia et al. 2016). Additionally, behaviour biomarkers do not require animal sacrifices even at long-term toxicity monitoring. The swimming behaviour is a routine process of fish that governs other essential behavioural activities such as searching for feed, protecting from predators, reproduction, Etc. The swimming behaviour of a fish might affect under stress conditions. Thus, we can observe different stages (safe, acclimation, adjustment, or toxic) on the swimming response of fish (Ren et al. 2018). These behavioural changes could result in hyper- or hypo-activity. Generally, agitated (hyperactive) behaviour could occur under stress conditions when fish habitat is in the open environment. Suppose fish habitat is in an unescapable milieu. To elude themselves from the external stimuli, they could minimise the gill movement (increase distance between gill epithelium and the external environment) and water flow. This action could result in hypoactivity. This situation is an indication of the avoidance behaviour of fish. Noteworthy, avoidance behaviour could reveal fish's sensing capability to stressors. The significance of these endpoints could increase the ecological significance of risk assessment procedures. Behaviour anomalies associated with toxicant treatment can recover once fish are introduced to a toxicant free environment; thus, recovery responses are recognised as an assisting parameter in behavioural toxicology (Ren et al. 2021).

The continuous contamination of water systems has led to the development of reliable real-time monitoring approaches. Real-time ecological or biological monitoring is possible only with the computer-based apparatus. Thus, researchers developed different types of computer-based real-time monitoring sensors and systems in recent years. Noteworthy, online monitoring systems are inexpensive, user-friendly, require no human interference, and harmless to test specimens (Pasternak et al. 2017; Anas et al. 2020). Real-time monitoring technologies based on fish swimming behaviour are improved much in recent years, which signifies the significance of behavioural toxicology (Zhang et al. 2015). Long-term eco-toxicity assessment is possible using online behaviour monitoring systems. The generated behaviour data can be analysed using computer software, making online behaviour assessments more manageable and efficient monitoring systems (Xia et al. 2016).

This study's hypothesis is to use fish swimming behaviour as an early warning non-invasive biomarker to assess the impacts of waterborne contaminants. We also highlight the importance of online monitoring systems in continuous eco-toxicity assessments in this study. To evaluate the eco-toxicity of commonly used disinfectants on non-target organisms, we exposed zebrafish to different concentrations of $\mathrm{NaOCl}$ for $360 \mathrm{~h}$. We analysed swimming behaviour using an online monitoring system (OMS). The recovery study 
(after $\mathrm{NaOCl}$ treatment period, zebrafish were introduced to normal water) conducted for $144 \mathrm{~h}$.

\section{Materials and methods}

\section{Zebrafish care}

Healthy Danio rerio (AB wild-type, 5-6 months old, length $3.4 \pm 0.4 \mathrm{~cm}$, weight $0.4 \pm 0.1 \mathrm{~g}$ ) used in this study were obtained from our fish breeding laboratory (location: Institute of Environment and Ecology, Shandong Normal University, Jinan, China). Zebrafish were maintained in a recirculating aquaculture system (water was aerated by air bubblers and purified with activated carbon and filter cotton, continuously) at constant photoperiods (light - $12 \mathrm{~h}$ : dark - $12 \mathrm{~h}$ ). Rearing conditions were set optimum with the following water-quality parameters, temperature $\left(27 \pm 0.5^{\circ} \mathrm{C}\right)$, water hardness $(250 \pm 20 \mathrm{mg} / \mathrm{L})$, and $\mathrm{pH}(7.8 \pm 0.2)$. Zebrafish were fed twice a day with commercially available fish feed. We removed uneaten feed and fish faecal matters manually at regular (at least $1 \mathrm{~h}$ later to feeding) intervals. We used both sexes of zebrafish for tests. We avoided abdomen elongated zebrafish for tests.

\section{Procurement of $\mathrm{NaOCl}$ and preparation of test concentrations}

$\mathrm{NaOCl}$ was purchased from NAIS Group, Co., Ltd., China. $\mathrm{NaOCl}$ contaminated water was prepared by mixing $\mathrm{NaOCl}$ (appropriate amount, based on the requirement) in water (collected from the rearing system). Control: $0 \mu \mathrm{L}$ of $\mathrm{NaOCl}$, Treatment I: $0.0025 \%$ v/v, Treatment II: $0.005 \%$ v/v, Treatment III: $0.0075 \% \mathrm{v} / \mathrm{v}$, and Treatment IV: $0.01 \% \mathrm{v} / \mathrm{v}$. NaOCl contaminated water renewed $(5 \mathrm{~L})$ at every $96 \mathrm{~h}$ of the study periods.

\section{Online behavioural toxicity assessment}

We used an OMS to assess the zebrafish's swimming strength (Fig. 1). The main components of OMS are a fish chamber with metal sensors, a water-flow system (water tank, peristaltic pump), and a normal computer (central processing unit-CPU, monitor, and software). Fish chamber (material: high-grade plastic, size: $5 \mathrm{~cm}$ in diameter and $7 \mathrm{~cm}$ in length, shape: cylindrical) has two opening edges (top and bottom) and two pairs of metal electrodes (sensors) on its inner surface. Metal sensors are connected to the CPU through copper-coated PVC cables. The water-flow system connects the fish chamber with rubber tubes. Water from the tank pumped at $30 \mathrm{~mL} / \mathrm{min}$ flows to the fish chamber through the peristaltic pump. The bottom valve of the fish chamber receives water from the tank, and the top valve ousts the water back to the same tank to complete a water cycle. The metal sensors are the automatic samplers of the OMS. The CPU and software process the samples through $\mathrm{A} / \mathrm{D}$ transformers (analogue to digital convertor) and display them on the computer monitor. System calibrations were performed with and without zebrafish in the fish chamber at constant water flow. We managed the sensing capacity of the sensors to harvest behaviour strength of fish between 0 and 1 to determine no movement and full movement, respectively. The signal acquisition and transmission of the OMS are shown in Fig. 1. The sensor senses the fish movement by touch evoked electrical impulse. The sensors generate electrical signals. One pair of sensors sends a high frequency of the electrical signal of altering current, and the electrical signal was received by another pair of sensors in the fish chamber. The A/D transformers digitalised this electrical signal. The software in the computer analyses these digitalised signals. The result is displayed as a line graph on the computer monitor.

Main group: zebrafish (three numbers) were randomly collected from the rearing system and housed in the OMS fish chamber (single chamber). Zebrafish were starved for $24 \mathrm{~h}$ before the commencement of the behavioural tests. Nevertheless, they were fed once a day with regular feed during the tests. An appropriate amount of $\mathrm{NaOCl}$ (Treatment I: $0.0025 \% \mathrm{v} / \mathrm{v}$ ) was mixed in the tank connected to the fish chamber. Replicates: Simultaneously, three replicates were also maintained. Similar setups were upheld for the control (without adding $\mathrm{NaOCl})$, Treatment II $(0.005 \% \mathrm{v} / \mathrm{v})$, Treatment III $(0.0075 \% \mathrm{v} / \mathrm{v})$, and Treatment IV $(0.01 \% \mathrm{v} / \mathrm{v})$ groups. We used water from the rearing system to perform all tests. We also maintained the water-quality parameters and photoperiods similar to the rearing system.

We continuously monitored the behavioural toxicity of $\mathrm{NaOCl}$ for $360 \mathrm{~h}$ with normal photoperiods (light$12 \mathrm{~h}$ : dark-12 h). We conducted the recovery capability of zebrafish to $\mathrm{NaOCl}$ toxicity for $144 \mathrm{~h}$ with regular photoperiods (light-12 h : dark-12 h).

\section{Data analysis}

We used MATLAB Environments (MATLAB 2009, @ 1984-2009, The Math-Works, Inc.) to calculate the Mean value from the OMS dataset. Standard deviation (SD) was calculated using an MS-Excel worksheet. We used Statistical Product and Service Solutions (SPSS 16.0) to execute a general linear model (univariant analysis and Duncan's multiple range tests-DMRT). We used MATLAB to process the real-time data and obtain figures for swimming strength, autocorrelation, and self-organising map (SOM). The Mean 


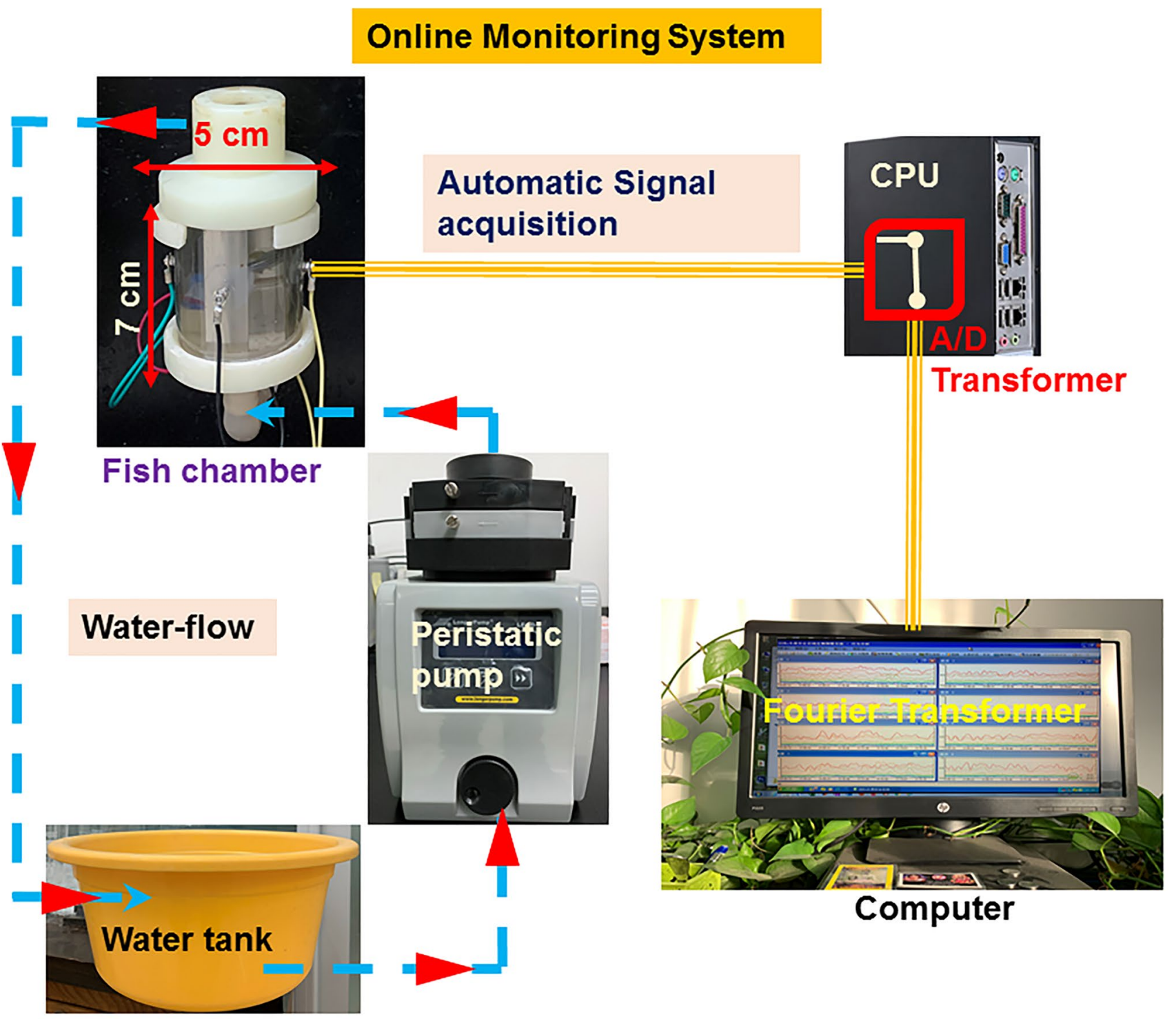

\section{Automatic Signal Acquisition and Processing}

Fish chamber

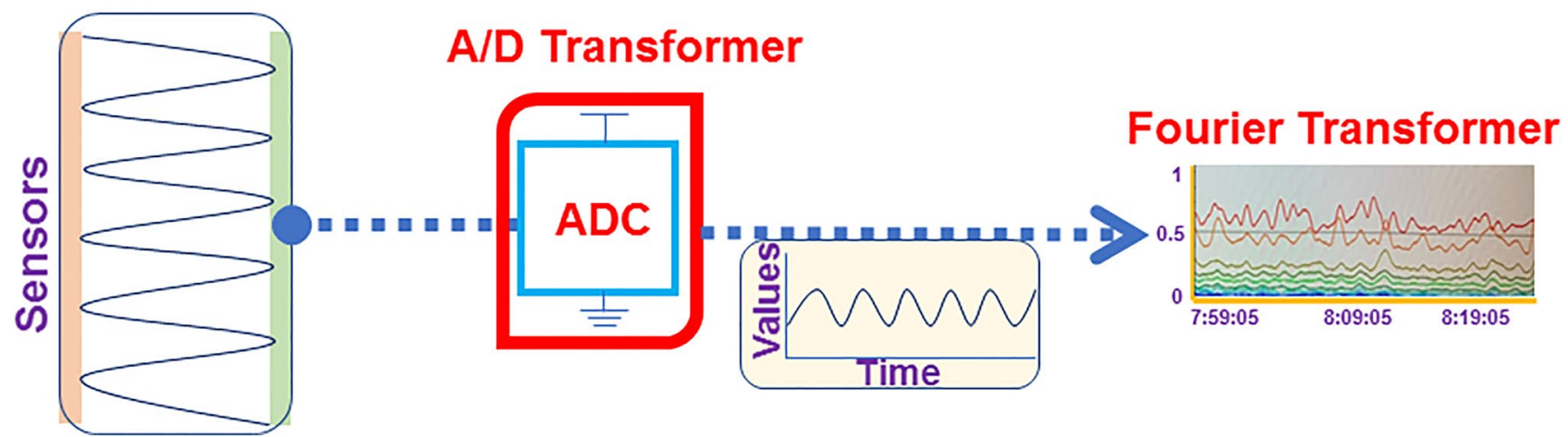

Fig. 1 Water-flow and automatic signal acquisition processes of online monitoring system (OMS) 
of every hour was used for all analyses. We used different file format for SOM (text-tab delimited.txt), autocorrelationMS Office-Excel worksheet-.xlsx) (pls. see Suppl Material. docx).

Circadian differences were calculated by using the formula in MS-Excel worksheet:

Time delay $\mathrm{D}(\mathrm{AVN}-\mathrm{AVD})=\frac{(\mathrm{AVD}-\mathrm{AVN})}{\mathrm{AVN}} \times 100 \%$

where AVN and AVD are the average value of night and day time, respectively.

\section{Results}

We showed real-time swimming behaviour $(360 \mathrm{~h})$ of the control and $\mathrm{NaOCl}$ treatment (Treatment I, II, III, and IV) groups in Fig. 2. The behaviour strength of the control group was found higher during the daytime and lowered during the night. A series of auxiliary actions have also resulted in the control group during the daytime. The behaviour strength of the $\mathrm{NaOCl}$ treatment groups was affected when compared to the control group. We visualised a series of abnormal, readjustment, and undifferentiated actions on the $\mathrm{NaOCl}$ treatment groups. However, we visualised a few auxiliary actions in the $\mathrm{NaOCl}$ treatment groups. The behaviour strength of the $\mathrm{NaOCl}$ Treatment I group is predominantly similar to the control group. Behaviour strength was partially identical

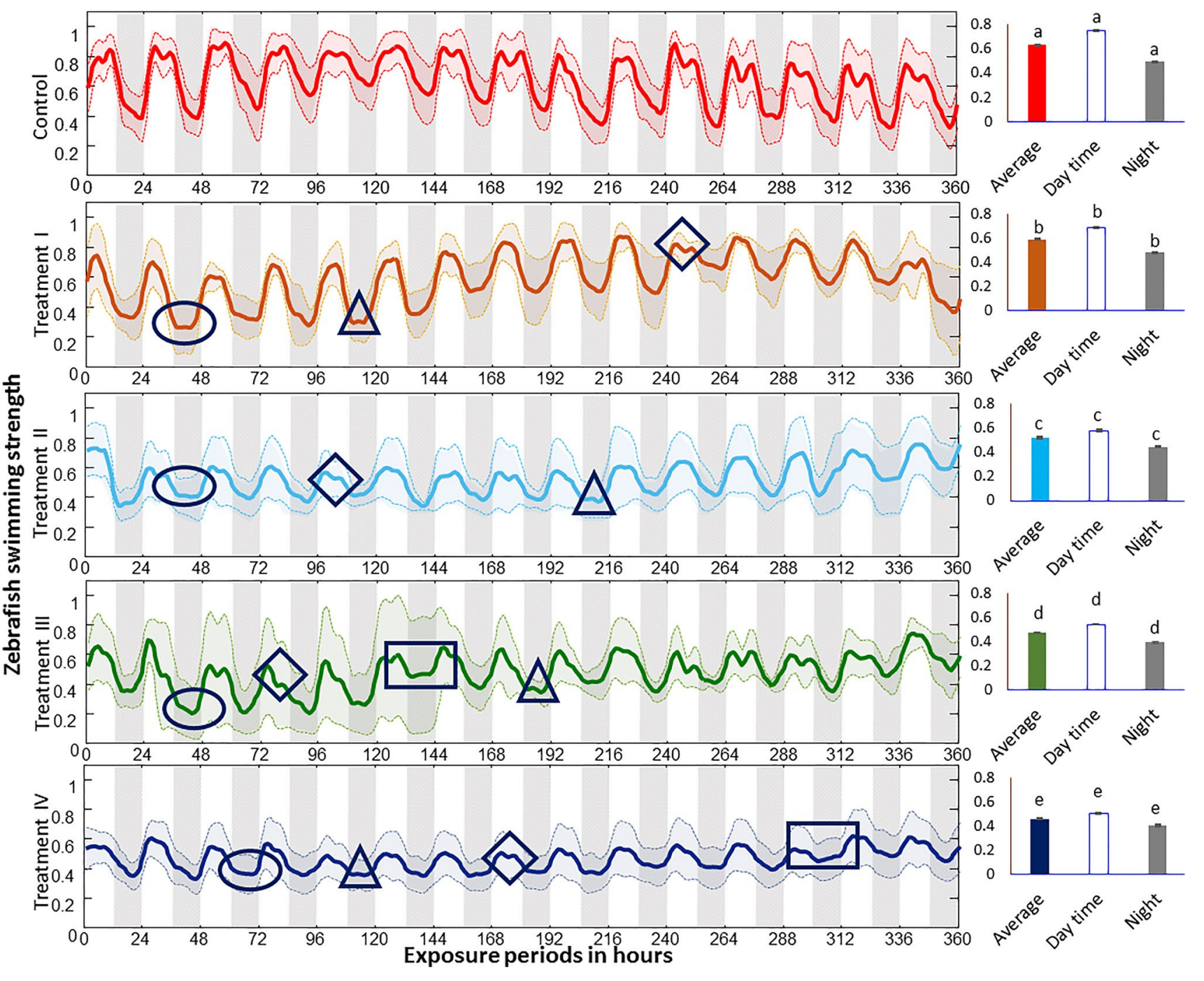

Fig. 2 Real-time swimming behaviour of zebrafish for $360 \mathrm{~h}$ of study periods. Solid lines and shaded dotted lines signify real-time swimming strength and S.D., respectively. Night of the study periods represented in shadow bars on the behaviour strength. Bar graphs beside behaviour strength of each group illustrate the differences in the behaviour strength at different photoperiods. Lowercase alphabets above the bars reveal statistical differences (DMRT, $p<0.001$ ) among other groups. Symbols on the behaviour strength: oval, diamond, square box, and triangle to represent abnormal, auxiliary, undifferentiated, and readjustment actions 

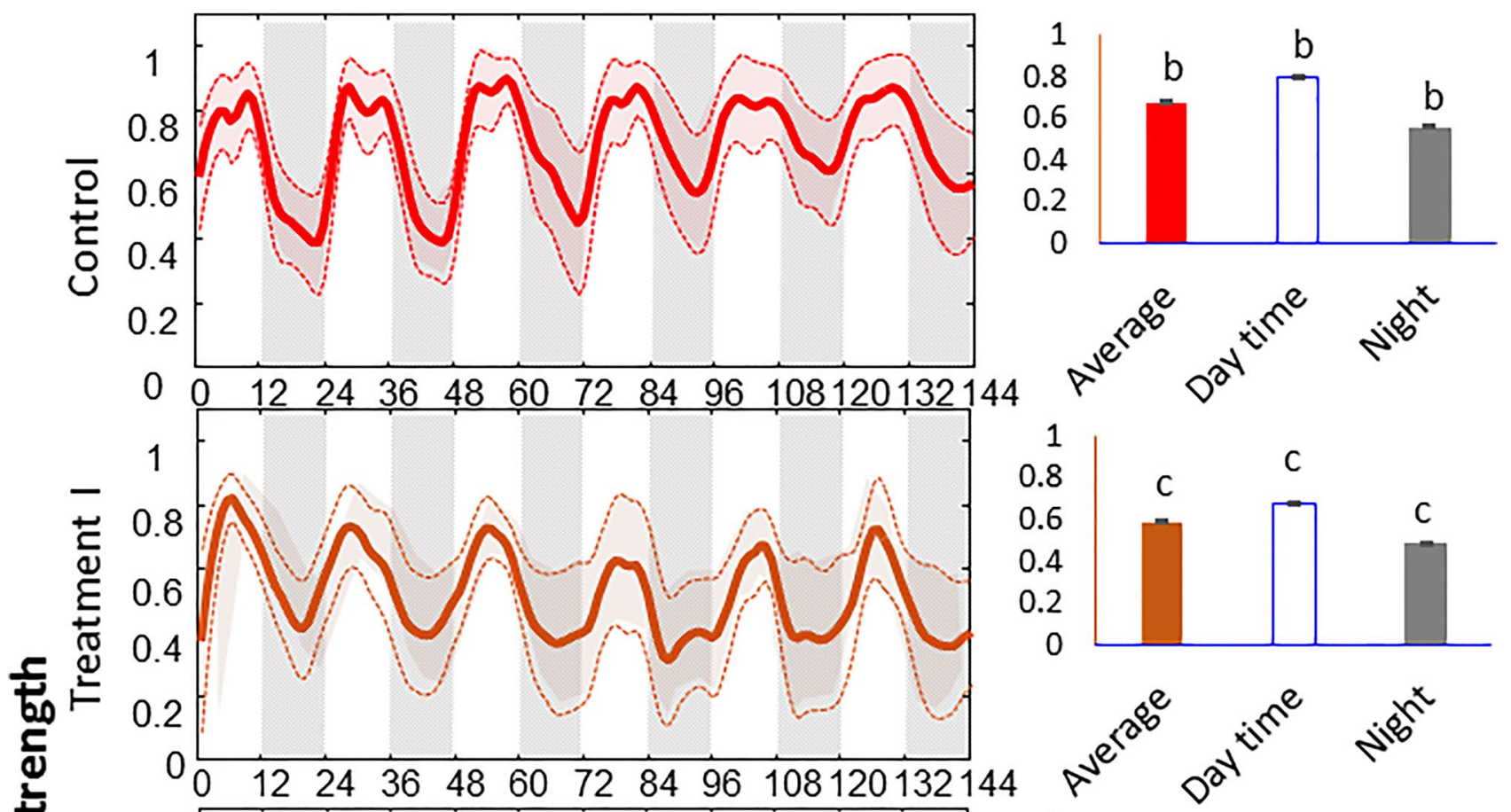

索

$$
\text { 告 }
$$$$
\text { N }
$$

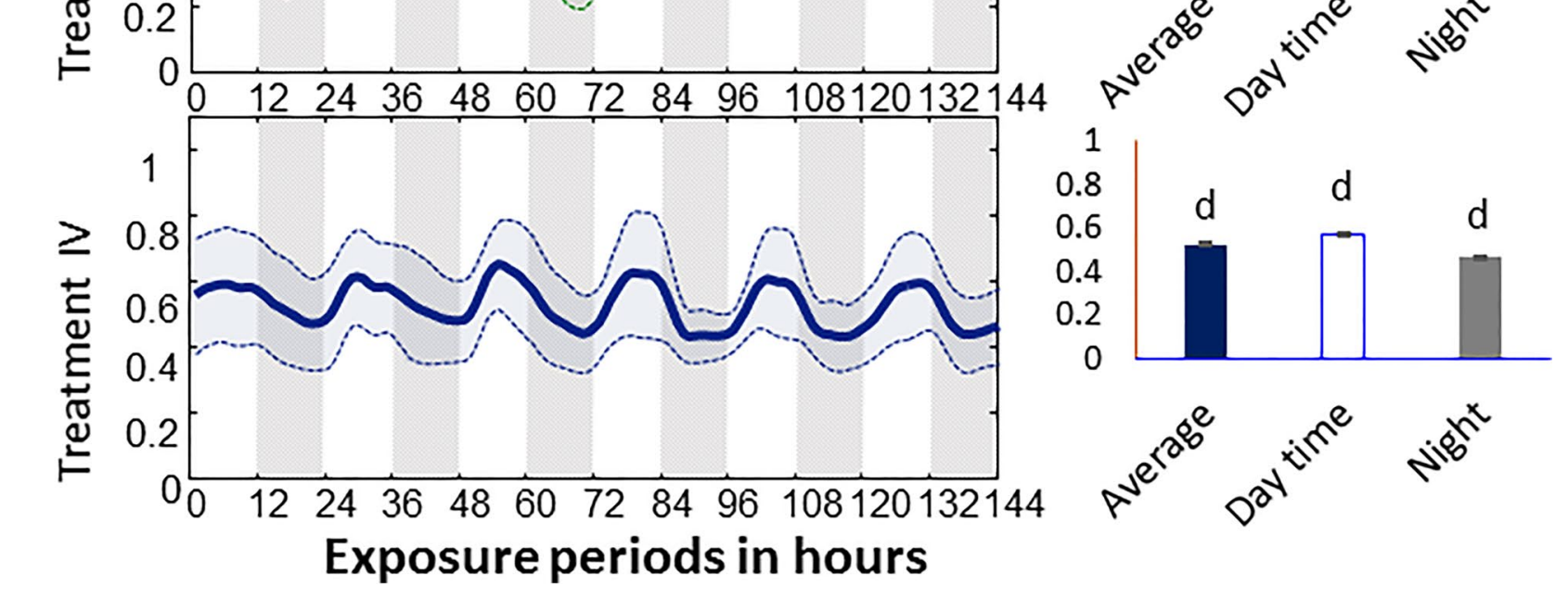


4Fig. 3 Recovery responses of zebrafish (144 h). Solid lines and shaded dotted lines signify real-time swimming strength and S.D., respectively. Night of the study periods represented in shadow bars on the behaviour strength. Bars beside behaviour strength of each group represent the differences in the behaviour strength at different photoperiods. Lowercase alphabets above the bars reveal statistical differences (DMRT, $p<0.001$ ) among other groups

to the control group in both $\mathrm{NaOCl}$ Treatment II and III groups. A series of undifferentiated actions have occurred in both Treatment III and IV groups. Among $\mathrm{NaOCl}$ treatment groups, behaviour strength affected the Treatment IV group immensely. Differences in behaviour strength of each group at different photoperiods are illustrated in bars. Overall, swimming behaviour declined significantly $(p<0.001)$ in $\mathrm{NaOCl}$ treatment groups compared to the control group. Bars reveal that zebrafish swimming activity was higher during the daytime when compared to the night.

We illustrated recovery responses of zebrafish for $144 \mathrm{~h}$ study periods in Fig. 3. Zebrafish swimming strength improved under-recovery study periods in all $\mathrm{NaOCl}$ treatment groups. However, $\mathrm{NaOCl}$ Treatment groups (except $\mathrm{NaOCl}$ Treatment I) were not similar to the control group. Not many alterations have occurred under control and $\mathrm{NaOCl}$ Treatment I exposure compared to $360 \mathrm{~h}$ of study periods. When compared among $\mathrm{NaOCl}$ treatment groups, zebrafish swimming strength greatly improved under Treatment II. Observed recovery responses were statistically significant $(p<0.001)$.

As shown in Table 1, differences in swimming strength were statistically significant $(p<0.001)$ among the factors such as groups, days, photoperiods, groups and days, groups and photoperiods, days and photoperiods, and groups and days and photoperiods. Adjusted " $r$ " squared for $360 \mathrm{~h}$ and $144 \mathrm{~h}$ (recovery study) study periods were $7.72 \%$ and $7.96 \%$, respectively, which reveal a strong association between the factors.

The light period is 8:00 a.m. to 7:59 p.m. every day, and the dark period is 8:00 p.m. every day to 7:59 a.m. on the next day. Values represent Mean \pm S.D for each group.

We tabulated zebrafish swimming differences at the different time-delayed trials in Table 2. Statistical analysis reveals that zebrafish swimming strength was higher during daytime (AVD) in 360 and $144 \mathrm{~h}$ exposure periods. The control group AVD maximum percentage change resulted for $\mathrm{NaOCl}$ Treatment IV group, at $360 \mathrm{~h}(32.7 \%)$ and $144 \mathrm{~h}(28 \%)$ study periods. A minimum percentage change occurred for $\mathrm{NaOCl}$ Treatment I (360 h: $8.7 \%)$ and Treatment II (144 h: $0.2 \%$ ). A maximum AVN percentage change resulted for $\mathrm{NaOCl}$ Treatment III (360 h: $20.1 \%$ ) and Treatment II (144 h: 28.3\%) groups. A minimum AVN percentage change occurred for $\mathrm{NaOCl}$ Treatment I for $360(2.8 \%)$ and $144(12.8 \%) \mathrm{h}$ of study periods. Among the $\mathrm{NaOCl}$ treatments, maximum percentage differences between AVN and AVD resulted in the Treatment I group (43.3\%) for $360 \mathrm{~h}$ of study periods and the Treatment III group (47.8\%) for $144 \mathrm{~h}$ of study periods. A minimum percentage change occurred for the Treatment IV group (24.9\%) and the Treatment II group (11.7\%) for 360 and $144 \mathrm{~h}$ study periods. Observed behavioural differences for AVD (daytime) and AVN (night) were statistically significant at $p<0.05$. The light period is 8:00 a.m. to 7:59 p.m. every day, and the dark period is 8:00 p.m. every day to 7:59 a.m. on the next day. Values represent Mean \pm S.D for each group. ${ }^{\text {a }}$ Indicates $p<0.05$ of different treatments compared to the control group.

$\mathrm{SOM}$ profiles for the control and different $\mathrm{NaOCl}$ treatment groups are illustrated in Fig. 4. Daytime and night of the study periods were differentiated by ordination map, in which the upper zone is night and the lower zone is daytime. Six clusters are classified in this study. We represented each cluster in different colours in the dendrogram. The Ward linkage method calculates the closeness between each cluster. Clusters 2 and 6 represent the daytime of the study periods. And, Clusters 3 and 4 signify the night of the study periods. Figure 4 illustrates SOM profiles for the control, $\mathrm{NaOCl}$ Treatment I, II, III, and IV groups. Zebrafish (under $0 \% \mathrm{NaOCl}$ ) swimming activity was higher during the daytime and decreased at night. Similar responses have resulted in $\mathrm{NaOCl}$ treatment groups. However, SOM profiles for $\mathrm{NaOCl}$ treatment groups did not completely match the control group SOM.

SOM profiles for zebrafish under-recovery study periods are exemplified in Fig. 5. The upper and lower zones of the ordination map signify night and daytime, respectively. We visualised six clusters in the dendrogram. The closeness between clusters 1 and 4 indicates day, and clusters 2 and 3 imply the night of the study periods. We visualised differences and partial matching of swimming strength in this study. SOM profiles for $\mathrm{NaOCl}$ treatment groups were predominantly matching with the control group.

We exemplified autocorrelation analysis to determine periodicity changes of zebrafish swimming strength for $360 \mathrm{~h}$ and $144 \mathrm{~h}$ study periods in Fig. 6. Clear swinging peaks (diurnal pattern) represent that the circadian rhythms of the control group were not affected throughout the study periods. The circadian rhythms were affected under $\mathrm{NaOCl}$ treatments (360 h study periods) (Fig. 6a). Swinging peaks for $\mathrm{NaOCl}$ treatment groups were not similar to the control group. Nocturnal behaviour resulted in $\mathrm{NaOCl}$ treatment periods. We noticed a gradual biphasic trend at minus series (nocturnal) for $\mathrm{NaOCl}$ Treatment I group. In other $\mathrm{NaOCl}$ treatment groups, peaks at minus series fluctuate recurrently. The control and $\mathrm{NaOCl}$ treatment groups under-recovery study $(144 \mathrm{~h})$ periods showed clear swinging peaks throughout the study periods, indicating that the circadian rhythm was not affected under normal (recovery) conditions (Fig. 6b). 
Table 1 Tests between subjects' effects for $\mathrm{NaOCl}$ treatment and recovery groups

\begin{tabular}{|c|c|c|c|c|}
\hline \multirow[t]{2}{*}{ Factors } & \multicolumn{2}{|c|}{$\mathrm{NaOCl}$ treatment } & \multicolumn{2}{|c|}{ Recovery } \\
\hline & $F$ valu & & $F$ valu & \\
\hline Groups & 359.5 & \multirow{7}{*}{$\begin{array}{l}\text { Significance } \\
p<0.001 \\
\text { Adjusted } \boldsymbol{r} \text { squared } \\
7.72 \%\end{array}$} & 352.0 & \multirow{7}{*}{$\begin{array}{l}\text { Significance } \\
p<0.001 \\
\text { Adjusted } \boldsymbol{r} \text { squared } \\
7.96 \%\end{array}$} \\
\hline Days & 28.4 & & 1.0 & \\
\hline Photoperiods & 2.5 & & $1.1^{\#}$ & \\
\hline Groups and Days & 24.6 & & 9.3 & \\
\hline Groups and Photoperiods & 67.6 & & 34.9 & \\
\hline Days and Photoperiods & 3.8 & & $3.2^{*}$ & \\
\hline Groups and Days and Photoperiods & 1.8 & & 2.6 & \\
\hline
\end{tabular}

\#Not significant

*Significant at $p<0.05$

\section{Discussion}

The environmental spreading of the virus that causes severe acute respiratory syndrome coronavirus (SARS-CoV-2) on humans can be prevented by disinfectants. Thus, regulatory agencies and public health organisations made recommendations to disinfect regularly handling objects and boarding places with household bleach, soaps, alcohol wipes, and handwash (Rivera et al. 2020; Eldeirawi et al. 2021). Among different kinds of disinfectants (alcohols, aldehydes, bases, biguanides, chlorine, glycols, iodophors, metal ions, organic acids, phenolic compounds, surfactants, thiazoles), the use of chlorine-based disinfectants $(>0.5 \mathrm{mg} / \mathrm{L}$ residual free chlorine) increased globally during the SARS-CoV-2 pandemic (Christen et al. 2017; Dhama et al. 2021). Furthermore, the recommended levels for chlorine-based disinfectants on medical applications were $500 \mathrm{mg} / \mathrm{L}$ (without obvious contamination) and $1000 \mathrm{mg} / \mathrm{L}$ (with obvious contamination) (Wang et al. 2020). Thus, the occurrence of disinfectants in the water ecosystem is well predictable (Amorim et al. 2017). A maximum concentration of $2 \mathrm{mg} / \mathrm{L}$ of NaOCl was used in WWTP at Junglang (Park et al. 2016). The concentration of $\mathrm{NaOCl}$ in the aquatic environment might occur at several hundreds of microlitres. No observed effect concentration and lowest observed effect concentration for chlorine-based disinfectants are 0.002 and $0.004 \%$ $\mathrm{v} / \mathrm{v}$, respectively (as mentioned in Subpriamaniyam 2021). We chose $0.0025,0.005,0.0075$, and $0.01 \% \mathrm{v} / \mathrm{v}$ concentration to study the potential ecotoxicity of $\mathrm{NaOCl}$. Disinfectants can persist in the water system (Ton et al. 2012). The occurrence of $\mathrm{NaOCl}$ in the aquatic environment might pose health effects on biota (Deere et al. 2020). Hence, different aquatic biological models, such as fish, mussels, planktons, and amphibians, were considered for water quality monitoring. Among these bioindicators, fish are recognised as toxicity models among aquatic organisms because fish are the higher trophic organism, susceptible to environmental changes, biochemical functioning is similar to humans, easy to maintain/handle, and inexpensive. Among fishes, zebrafish are widely used to assess waterborne disinfectants' potential impacts (as mentioned in Ton et al. 2012). In this study, we have chosen zebrafish as an animal model to

Table 2 Comparison of zebrafish swimming strength under $\mathrm{NaOCl}$ and recovery Mean values in different photoperiods

\begin{tabular}{|c|c|c|c|c|c|c|}
\hline \multirow[t]{2}{*}{ Exposure periods } & \multirow[t]{2}{*}{ Groups } & \multicolumn{5}{|l|}{ Parameters } \\
\hline & & AVD & $\begin{array}{l}D \text { (compared to } \\
\text { control) } \%\end{array}$ & AVN & $\begin{array}{l}D \text { (compared to } \\
\text { control) } \%\end{array}$ & $\begin{array}{l}D(\mathrm{AVN}- \\
\mathrm{AVD}) \%\end{array}$ \\
\hline \multirow{5}{*}{$\begin{array}{l}360 \mathrm{~h} \\
(8 \mathrm{a} . \mathrm{m} . \text { of } 1 \mathrm{st} \text { day to } 7: 59 \text { am of } 16 \mathrm{st} \text { day) }\end{array}$} & Control & $0.75 \pm 0.06$ & & $0.49 \pm 0.07$ & & 52.4 \\
\hline & Treatment I & $0.68 \pm 0.10^{\mathrm{a}}$ & 8.7 & $0.48 \pm 0.12^{\mathrm{a}}$ & 2.8 & 43.3 \\
\hline & Treatment II & $0.58 \pm 0.05^{\mathrm{a}}$ & 22.6 & $0.45 \pm 0.06^{\mathrm{a}}$ & 9.3 & 30.1 \\
\hline & Treatment III & $0.54 \pm 0.07^{\mathrm{a}}$ & 27.7 & $0.39 \pm 0.09^{\mathrm{a}}$ & 20.1 & 37.9 \\
\hline & Treatment IV & $0.50 \pm 0.04^{\mathrm{a}}$ & 32.7 & $0.40 \pm 0.04^{\mathrm{a}}$ & 17.8 & 24.9 \\
\hline \multirow{5}{*}{$\begin{array}{l}144 \mathrm{~h} \\
\text { ( } 8 \text { a.m. of } 1 \text { st day to } 7: 59 \text { am of } 7 \text { st day) }\end{array}$} & Control & $0.80 \pm 0.02$ & & $0.56 \pm 0.08$ & & 43.6 \\
\hline & Recovery I & $0.67 \pm 0.03^{\mathrm{a}}$ & 15.8 & $0.48 \pm 0.06^{\mathrm{a}}$ & 12.8 & 38.8 \\
\hline & Recovery II & $0.80 \pm 0.02^{\mathrm{a}}$ & 0.2 & $0.71 \pm 0.02^{\mathrm{a}}$ & 28.3 & 11.7 \\
\hline & Recovery III & $0.61 \pm 0.05^{\mathrm{a}}$ & 23.4 & $0.41 \pm 0.05^{\mathrm{a}}$ & 25.6 & 47.8 \\
\hline & Recovery IV & $0.57 \pm 0.01^{\mathrm{a}}$ & 28.2 & $0.47 \pm 0.02^{\mathrm{a}}$ & 16.1 & 23.0 \\
\hline
\end{tabular}

The light period is 8:00 a.m. to 7:59 p.m. every day, and the dark period is 8:00 p.m. every day to 7:59 a.m. on the next day. Values represent Mean \pm S.D for each group. Indicates $p<0.05$ of different treatments compared to the control group 
assess the toxic effects of $\mathrm{NaOCl}$ on non-target organisms. Exposure to waterborne contaminants affects fish swimming behaviour even at lower concentrations $(\mu \mathrm{g} / \mathrm{L})$ (Brodin et al. 2013, 2017). Concentration-dependent behaviour anomalies resulted in zebrafish under $\mathrm{NaOCl}$ treatments. Magalhaes et al. (2007) reported similar behaviour anomalies on zebrafish under $\mathrm{NaOCl}$ treatments, where the swimming activity decreased with increasing $\mathrm{NaOCl}$ concentration. In our previous studies, we also noticed a correlation between declined swimming activity of zebrafish with chemical concentrations (Zhao et al. 2020; Poopal et al. 2021; Ren et al. 2021). Declined swimming strength under $(360 \mathrm{~h}) \mathrm{NaOCl}$ treatments reveals the avoidance behaviour of zebrafish. Avoidance or escaping sign is a common response of fish to reveal stress in its environment. Continuous exposure to environmental stressors could affect the normal behavioural activity of fish; hyperactivity or hypoactivity is a sign of avoiding stress (Hong and Zha 2019). The fractal dimension of zebrafish swimming velocity increased under $\mathrm{NaOCl}-$ based aqueous solutions ( 0 to $0.005 \% \mathrm{v} / \mathrm{v}$ ) treatments (Nimkerdphol and Nakagawa 2008). The authors also noticed that water quality parameters increased zebrafish swimming trajectories under $\mathrm{NaOCl}$ treatments.

We visualised a series of abnormal, auxiliary, undifferentiated, and readjustment actions under $\mathrm{NaOCl}$ treatments.
Normally, fish swimming activity requires higher energy consumption. Under continuous environmental stress conditions, fish might cease swimming to conserve energy to cope with the stress, which could decline the swimming strength; thus, we can visualise abnormal behaviour strength. The term abnormal (Latin abnormis) means deviating from the normal. A series of abnormal actions were shown under $\mathrm{NaOCl}$ exposure periods, indicating that zebrafish sensed $\mathrm{NaOCl}$ toxicity and might activate its coping mechanisms against the toxicity. Acclimatisation is a typical survival strategy for fish under tolerable stress conditions. During acclimatisation, fish might undergo a series of adjustments. The occurrence of adjustments on fish purely depends on the strength of the stressors. The term auxiliary actions mean the occurrence of additional actions (adjustments). The occurrence of auxiliary actions during the daytime signifies acclimatised state of zebrafish to their current environment. Adjustment is the state of being adjusted to the current environmental change. Readjustment is adapting oneself again to the current environmental change. The occurrence of readjustment actions at night under $\mathrm{NaOCl}$ treatments indicates internal stress (the activation of detoxification and ejecting mechanisms). Under normal or tolerable stress conditions, the behavioural strength could be higher in the daytime and lower at night; this results in zig-zag patterns. When the
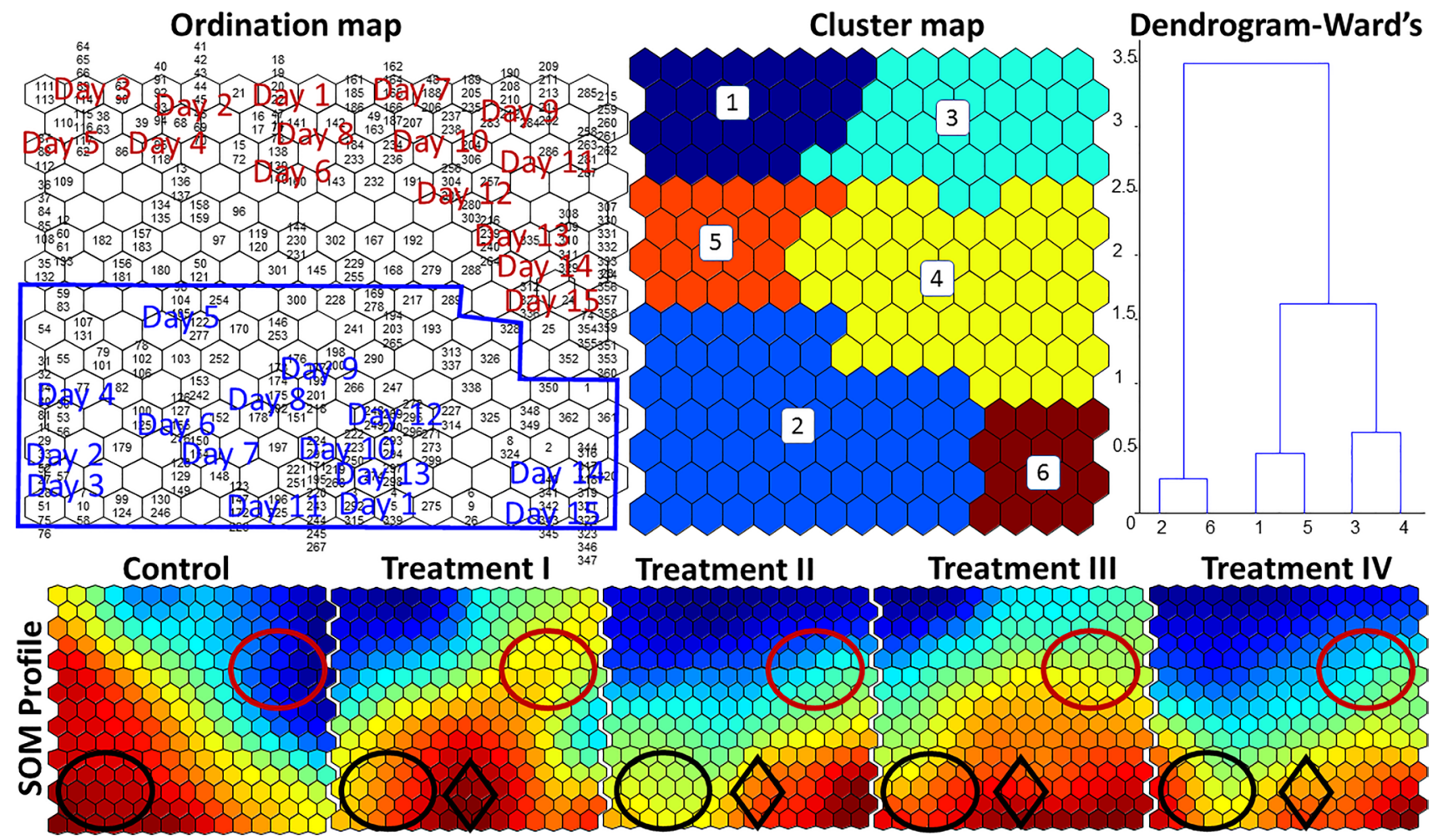

Fig. 4 SOM analysis for zebrafish swimming strength under $360 \mathrm{~h}$ study period. Ordination map-blue colour text and red colour text represents daytime and night of the study. SOM profiles-dark blue to dark red colour indicates lower to higher swimming strength. The symbol ring (red-night, black - daytime) and the diamond represent differences and partial matching in swimming strength 


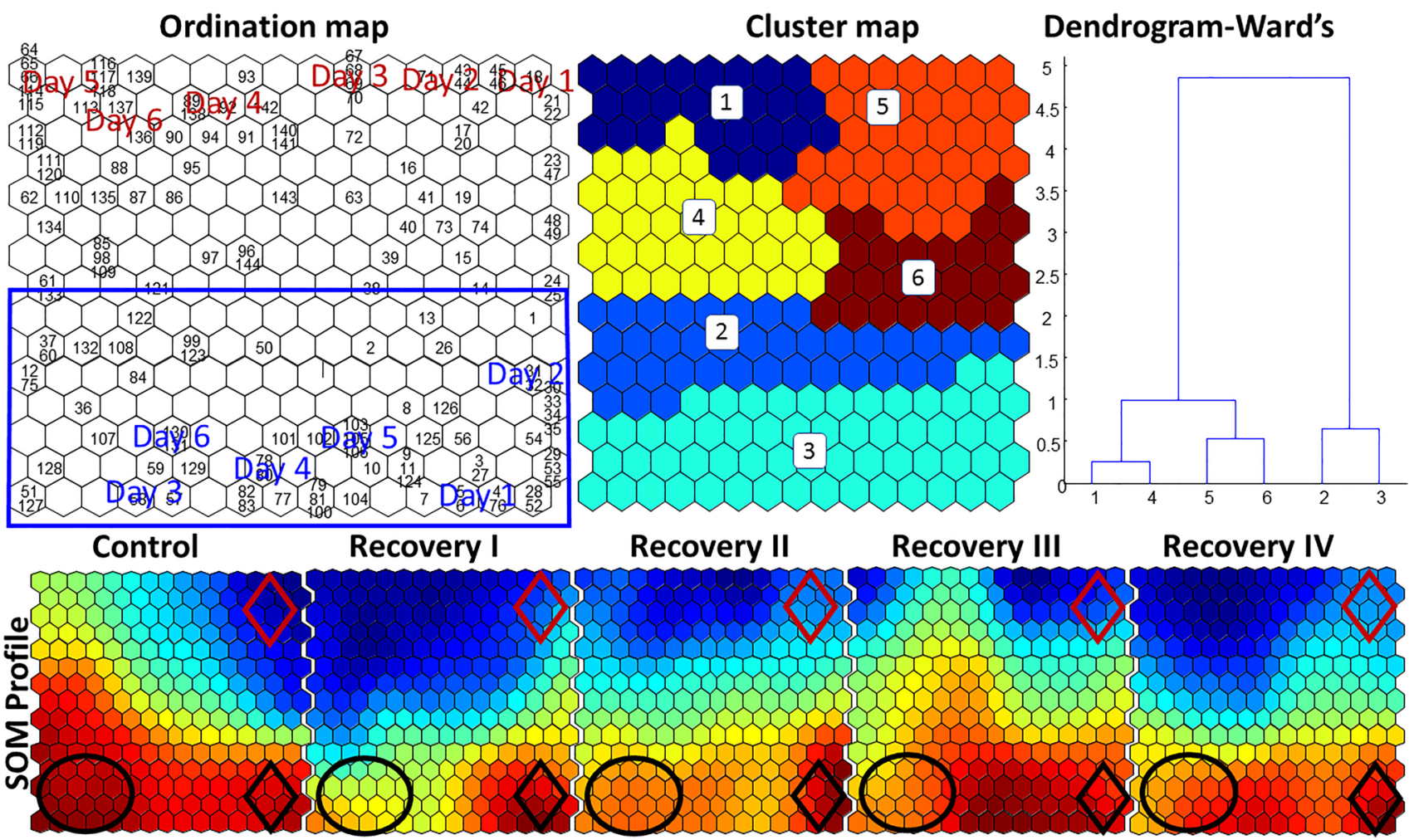

Fig. 5 SOM analysis for zebrafish swimming strength under $144 \mathrm{~h}$ (recovery) study period. Ordination map-blue colour text and red colour text represent daytime and night of the study. SOM profilesdark blue to dark red colour indicates lower to higher swimming

stress overwhelms the tolerance capacity of fish, the behaviour strength could be unspecifiable, not able to differentiate the action. We witnessed a series of undifferentiated behaviour strengths under higher concentrations of $\mathrm{NaOCl}$ (Treatment III and IV). The undifferentiated area on real-time data reveals that zebrafish's coping capacity was overwhelmed by $\mathrm{NaOCl}$ stress at higher concentrations.

Swimming performance is essential for survival for fish; chemical exposure could affect ion homeostasis, resulting in behavioural changes in fish (as mentioned in Goulding et al. 2013). $\mathrm{NaOCl}$ forms hydrogen cations and hypochlorite ions in the aquatic ecosystem, which could damage the membrane potential of cells and result in disruption of biochemical (including enzymes) and ion homeostasis mechanisms (LopezGalindo et al. 2010a,b). $\mathrm{NaOCl}$ entry through gill tissues might affect the tissue morphology, resulting in disruption of routine metabolism (ion-regulation mechanism, respiration, and excretion) of zebrafish; thus, alteration in swimming behaviour might occur. Exposure to commonly used disinfectants can generate reactive oxygen species in tissues and affect the antioxidant defence system of fish. Additionally, disinfectants can affect the biochemical and hormonal functioning of fish (Elia et al. 2006; Kim and Ji 2019). Swimming activity depends on the energy metabolism (biochemical activities) strength. The symbol ring and the diamond (red-night, blackdaytime) represent differences and partial matching in swimming strength

of an organism. The decline of swimming strength might result from internal stress (imbalanced energy metabolism of zebrafish) caused by $\mathrm{NaOCl}$. Painter et al. (2009) reported that waterborne chemicals could impair nervous cell signalling by binding or blocking synaptic receptors that could affect nerve impulse communication transmission; as a result, behaviour anomalies (declined behavioural performance) could occur on organisms. $\mathrm{NaOCl}$ treatment inhibited acetylcholine activity on Mytilus galloprovincialis under long-term exposure (LopezGalindo et al. 2010a). Thus, a decline in swimming activity indicates the neuro-toxic effect of $\mathrm{NaOCl}$ on zebrafish. However, internal stress (histological, biochemical, and hormonal changes) could recover considerably under normal conditions (without environmental stressors). It is shown through the recovery response of zebrafish. Zebrafish swimming strength increased after reintroducing to normal conditions (water without $\mathrm{NaOCl}$ ). A concentration-dependent improvement occurred in zebrafish swimming strength under-recovery periods. A similar result was observed on zebrafish under chemical treatments (Poopal et al. 2021).

Online biological behaviour monitoring systems are considered an important tool in early warning pollution assessments (Magalhaes et al. 2007). Noticeably, the observed behavioural anomalies have occurred at lower concentrations 
a)
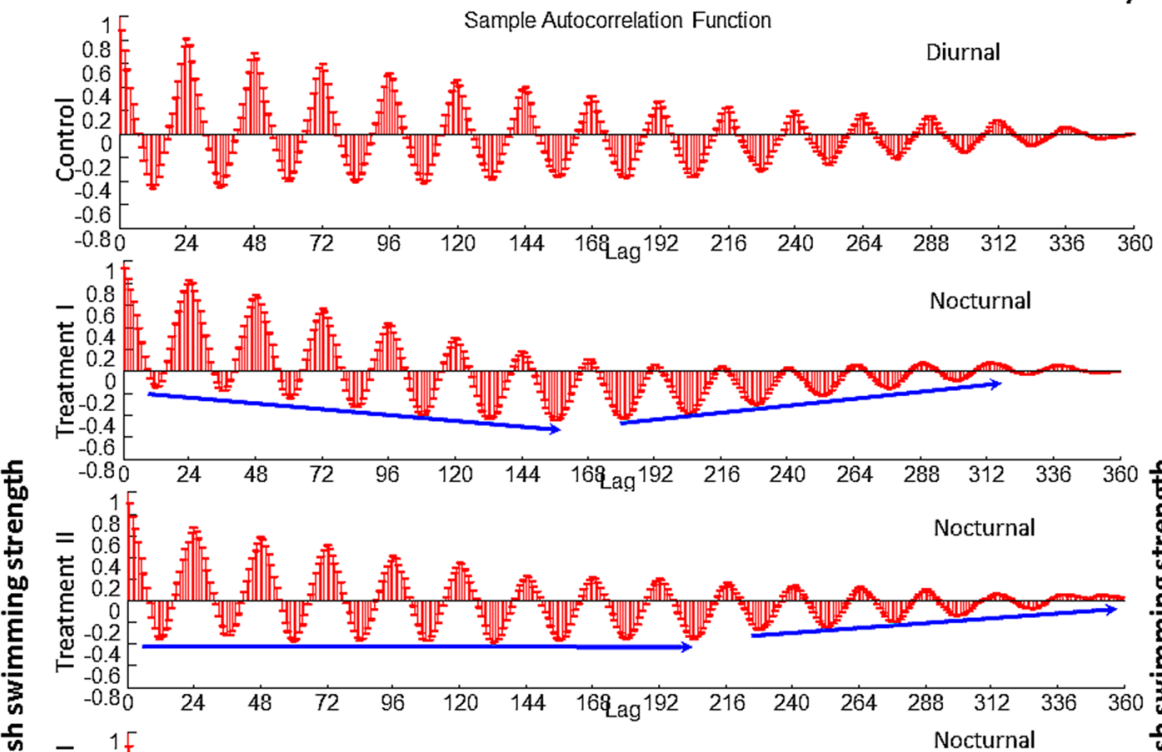

竞

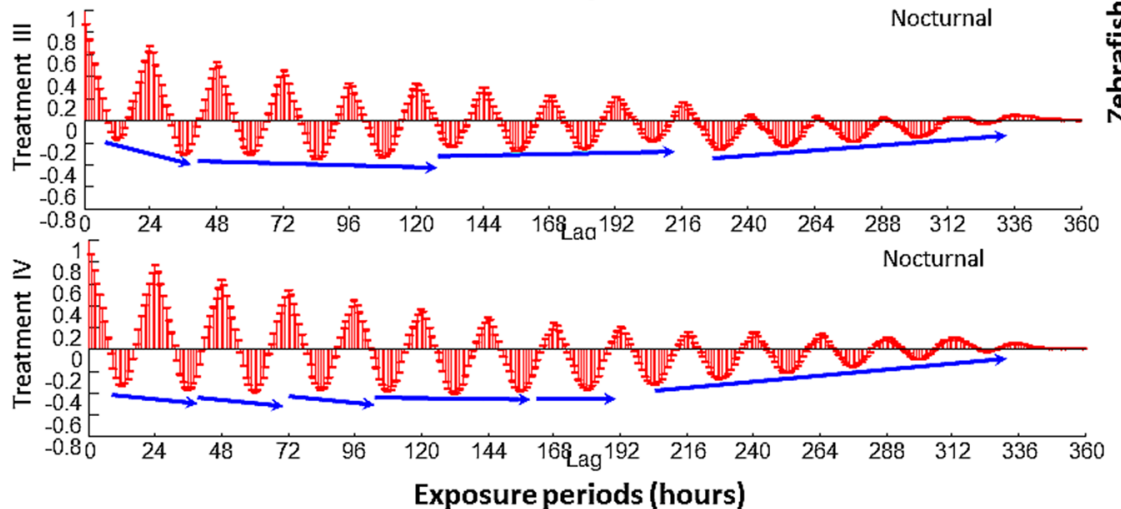

b)
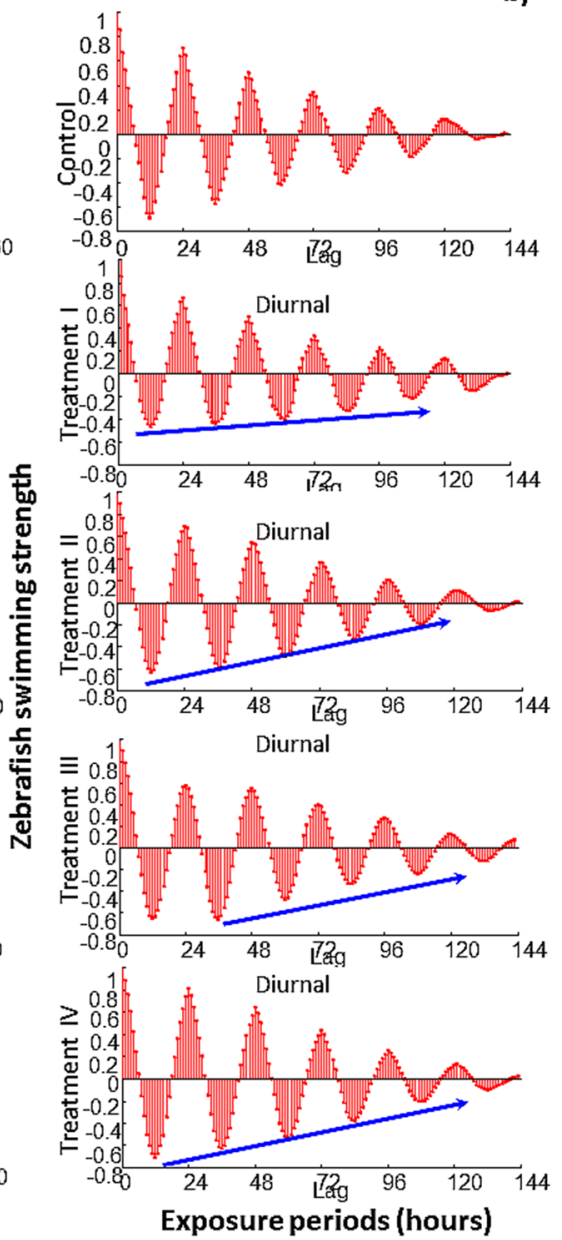

Fig. 6 Autocorrelation analysis. Periodicity changes occurred on zebrafish swimming strength at a) 360 h and b) 144 h study periods. Arrows specify continuity of behaviour strength at minus series

(even at $0.002 \% \mathrm{v} / \mathrm{v}$ ) of $\mathrm{NaOCl}$ treatments when compared to the concentration $(0.1 \mathrm{mg} / \mathrm{L})$ reported by Lopez-Galindo et al. (2010b) to cause histological, enzymological, and antioxidants changes on Solea senegalensis. A considerable amount of data was generated in this study using OMS, and the complexity in the data was solved by SOM. Changes in the behaviour activity of zebrafish were visualised on SOM. SOM differentiates the photoperiods of the study. We further analysed the data to determine changes in a circadian rhythm by autocorrelation analysis using MATLAB. Circadian rhythms are a fundamental behavioural trait and an essential factor governing organisms' physiology and behavioural activities (Melvin 2017; Zheng et al. 2021). Circadian rhythms have an essential role in sleep cycles, hormone secretion, blood pressure, and other routine life processes. Zebrafish is a good model organism for circadian rhythms studies (Doria et al. 2018; Yang et al. 2019). The circadian rhythms are endogenously driven, controlled by genes. Waterborne chemicals can affect circadian genes
(Liang et al. 2019). Shi et al. (2019) reported that transcriptional alteration of circadian rhythm genes on zebrafish could occur even at nanogram concentration of chemicals. Waterborne chemicals induce the circadian rhythms of fish through neuroendocrine pathways (Melvin 2017). Zhao et al. (2018) noticed a correlation between locomotory behaviour changes and disruption in clock genes of fish. Biocide exposure enhanced the circadian gene (clock la) expression, which resulted in behavioural changes in zebrafish (Yang et al. 2019). Changes in circadian rhythms reflect the adaptation of an organism. Circadian rhythms of $\mathrm{NaOCl}$ treatment groups were affected under $360 \mathrm{~h}$ study periods. This indicates that zebrafish recognised stressors and initiated their adaptation mechanisms. Circadian rhythms regulate immune processes in an organism (Ren et al. 2018), which can be adjusted due to chemical-mediated changes in internal homeostasis towards adaptation (Yang et al. 2018). Cellular free radicals and the circadian clock are interconnected; thus, alterations in antioxidants' defence mechanisms result 
in fish circadian disruption (Zheng et al. 2021). $\mathrm{NaOCl}$ has the potential to cross-link fibrinogen and affect blood plasma antioxidants defence mechanisms (immunostimulatory properties) (Manucat-Tan et al. 2021). Bao et al. (2019) reported that waterborne contaminants (perfluorooctane sulfonate) affect networking genes (hypothalamus-pituitary-gonadalliver axis) of female zebrafish. Biotransformation and detoxification processes mainly occur in the liver tissue; exposure to $\mathrm{NaOCl}$ might accelerate the formation of free radicals in the liver tissue of zebrafish. These free radicals might distribute through blood and cause an oxidative imbalance in zebrafish. Thus, circadian rhythm adjustments might result from internal stress (the antioxidant homeostasis).

In summary, under closed conditions, swimming behaviour could be an ideal indicator for ecotoxicological studies. The real-time swimming behaviour of fish can be quantified efficiently using OMS. We can analyse the OMS dataset for statistical differences using MATLAB and SPSS software. Zebrafish are highly sensitive to $\mathrm{NaOCl}$ toxicity, even at lower concentrations. The $\mathrm{NaOCl}$ is potentially a toxic substance at studied concentrations. A concentration-dependent toxic effect has resulted in this study. However, the $\mathrm{NaOCl}-$ mediated toxic effects are reversible (based on concentration) even at higher concentrations.

\section{Conclusion}

We exemplified the toxicity of $\mathrm{NaOCl}$ by monitoring (online) the swimming behaviour of zebrafish. The swimming strength of zebrafish was quantified efficiently using OMS. $\mathrm{NaOCl}$ induced behaviour anomalies on zebrafish even at lower concentrations $(0.0025 \% \mathrm{v} / \mathrm{v})$. We observed avoidance behaviour under $360 \mathrm{~h}$ of $\mathrm{NaOCl}$ exposure periods. Escaping or avoidance behaviour is not only stimulus-response but also reflects fitness of fish. Under prolonged toxicant exposure periods, avoidance behaviour might be overwhelmed by internal stress (morphological and biochemical changes), which could affect the fitness of fish. In that aspect, continuous contamination of $\mathrm{NaOCl}$ is a severe threat to aquatic biota. Circadian rhythm of zebrafish was affected under $360 \mathrm{~h} \mathrm{NaOCl}$ treatment periods; this is also a risk to organisms because adjustments in endogenous timing mechanism can affect organisms' adaptive capacity. The recovery responses (improvement in zebrafish swimming strength) reveal that the resulting behaviour anomalies under $360 \mathrm{~h}$ of study periods are based on stressor effects. This study highlighted the importance of behaviour toxicology towards water quality assessments. This study also signifies that swimming behaviour is a non-invasive biomarker in early warning signal approaches for toxicity studies. More biological behaviour studies are warranted to assess ecotoxic effects of emerging and unintentional or accidental pollutants. Future scope: Mathematical modelling based on the OMS dataset will be a promising method for eco-toxicity prediction assessments.

Supplementary Information The online version contains supplementary material available at https://doi.org/10.1007/s11356-021-18333-1.

Author contribution ZR: supervision and fund acquisition, YY: methodology, software, data curation, MR: review-final draft, LB: review—draft, RKP: methodology, software, data curation, writingoriginal and revised drafts, $\mathbf{Z R}$ and $\mathbf{Y Y}$ contributed equally.

Funding This study is financially supported by the National Natural Science Foundation of China (42077224), the Natural Science Foundation of Shandong (ZR2020MD122), Taishan Industry Leading Talents Fund (tscy20150707), and the Social Livelihood Major Project of Ji'nan (201807007).

Data availability Online monitoring dataset-supplementary file (data original.xlsx). Guidance for SOM and autocorrelation analysis (Suppl Material.docx).

\section{Declarations}

Ethics approval and consent to participate Not applicable.

Consent for publication Not applicable.

Competing interests The authors declare no competing interests.

\section{References}

Amorim J, Fernandes M, Vasconcelos V, Teles LO (2017) Evaluation of the sensitivity spectrum of a video tracking system with zebrafish (Danio rerio) exposed to five different toxicants. Environ Sci Pollut Res 24:16086-16096

Anas O, Wageeh Y, El-Din Mohamed H, Fadl A, ElMasry N, Nabil A, Atia A (2020) Detecting abnormal fish behavior using motion trajectories in ubiquitous environments. Proedia Comp Sci 175:141-148

Bao M, Huang WL, Au L, Zheng SK, Liu CX, Huang YN, Wu KS (2019) Exposure to perfluorooctane sulfonate based on circadian rhythm changes the fecundity and expression of certain genes on the hypothalamic-pituitary gonadal-liver axis of female zebrafish. Toxicol Appl Pharm 381

Brodin T, Fick J, Jonsson M, Klaminder J (2013) Dilute concentrations of a psychiatric drug alter behaviour of fish from natural populations. Science 339:814-815

Brodin T, Nordling J, Lagesson A, Klaminder J, Hellstrom G, Christensen B, Fick J (2017) Environmental relevant levels of a benzodiazepine (oxazepam) alters important behavioural traits in a common planktivorous fish, (Rutilus rutilus). J Toxicol Env Heal A 80:963-970

Centres for Disease Control and Prevention (CDC)-https://cfpub.epa. gov/giwiz/disinfectants/index.cfm

Choi K, Sim S, Choi J, Park C, Uhm Y, Lim E, Kim AY, Yoo SJ, Lee YJ (2021) Changes in handwashing and hygiene product usage patterns in Korea before and after the outbreak of COVID-19. Environ Sci Eur 33:79

Christen V, Faltermann S, Brun NR, Kunz PY, Fent K (2017) Cytotoxicity and molecular effects of biocidal disinfectants (quaternary 
ammonia, glutaraldehyde, poly(hexamethylene biguanide) hydrochloride PHMB) and their mixtures in vitro and in zebrafish eleuthero-embryos. Sci Total Environ 586:1204-1218

Dastagiri Reddy N, Elias AJ (2021) Chlorine and the chemistry of disinfectants, a fascinating journey-18th century to the COVID times. Resonance 26(3):341-366. https://doi.org/10.1007/ s12045-021-1135-y

de Oliveira JPJ, Estrela FN, Rodrigues ASD, Guimaraes ATB, Rocha TL, Malafaia G (2021) Behavioural and biochemical consequences of Danio rerio larvae exposure to polylactic acid bioplastic. J Hazard Mater 404

Deere JR, Moore S, Ferrey M, Jankowski MD, Primus A, Convertino M, Servadio JL, Phelps NBD, Hamilton MC, Chenaux-Ibrahim Y, Travis DA, Wolf TM (2020) Occurrence of contaminants of emerging concern in aquatic ecosystems utilised by Minnesota tribal communities. Sci Total Environ 724

Dhama K, Patel SK, Kumar R, Masand R, Rana J, Yatoo MI, Tiwari R, Sharun K, Mohapatra RK, Natesan S, Dhawan M, Ahmad T, Emran TB, Malik YS, Harapan H (2021) The role of disinfectants and sanitisers during COVID-19 pandemic: advantages and deleterious effects on humans and the environment. Environ Sci Pollut Res 28:34211-34228

Doria HB, Ferreira MB, Rodrigues SD, Lo SM, Domingues CE, Nakao LS, de Campos SX, Ribeiro CAD, Randi MAF (2018) Time does matter! Acute copper exposure abolishes rhythmicity of clock gene in Danio rerio. Ecotox Environ Safe 155:26-36

Duerschner J, Bartelt-Hunt S, Eskridge KM, Gilley JE, Li X, Schmidt AM, Snow DD (2020) Swine slurry characteristics as affected by selected additives and disinfectants. Environ Pollut 260

Eldeirawi K, Huntington-Moskos L, Nyenhuis SM, Polivka B (2021) Increased disinfectant use among adults with asthma in the era of COVID-19. Clinical Commun

Elia AC, Anastasi V, Dorr AJM (2006) Hepatic antioxidant enzymes and total glutathione of Cyprinus carpio exposed to three disinfectants, chlorine dioxide, sodium hypochlorite and peracetic acid, for superficial water potabilisation. Chemosphere 64:1633-1641

Emmanuel E, Keck G, Blanchard JM, Vermande P, Perrodin Y (2004) Toxicological effects of disinfections using sodium hypochlorite on aquatic organisms and its contribution to AOX formation in hospital wastewater. Environ Int 30:891-900

Falcao B, Marques M, Nunes B (2019) Behavioural and biochemical effects of the antifouler and antidandruff zinc pyrithione on the freshwater fish Gambusia holbrooki. Fish Physiol Biochem 45:1495-1512

Goh CF, Ming LC, Wong LC (2021) Dermatologic reactions to disinfectant use during the COVID-19 pandemic. Clinics Dermatol

Goulding AT, Shelley LK, Ross PS, Kennedy CJ (2013) Reduction in swimming performance in juvenile rainbow trout (Oncorhynchus mykiss) following sublethal exposure to pyrethroid insecticides. Comp Biochem Phys C 157:280-286

Holm SM, Leonard V, Durrani T, Miller MD (2019) Do we know how best to disinfect child care sites in the United States? A review of available disinfectant efficacy data and health risks of the major disinfectant classes. Am J Infect Control 47:82-91

Hong XS, Zha JM (2019) Fish behaviour: a promising model for aquatic toxicology research. Sci Total Environ 686:311-321

Huang J, Chen S, Ma X, Yu P, Zuo P, Shi B, Wang H, Alvarez PJ (2021) Opportunistic pathogens and their health risk in four fullscale drinking water treatment and distribution systems. Ecol Eng 160:106134

Kim H, Ji K (2019) Exposure to humidifier disinfectants induces developmental effects and disrupts thyroid endocrine systems in zebrafish larvae. Ecotox Environ Safe 184

Liang YQ, Huang GY, Zhen Z, Tian F, Hou L, Lin Z, Ying GG (2019) The effects of binary mixtures of estradiol and progesterone on transcriptional expression profiles of genes involved in hypothalamicpituitary-gonadal axis and circadian rhythm signaling in embryonic zebrafish (Danio rerio). Ecotox Environ Safe 174

Lopez-Galindo C, Vargas-Chacoff L, Nebot E, Casanueva JF, Rubio D, Mancera JM, Sole M (2010a) Sublethal responses of the common mussel (Mytilus galloprovincialis) exposed to sodium hypochlorite and Mexel (R) 432 used as antifoulants. Ecotox Environ Safe $73: 825-834$

Lopez-Galindo C, Vargas-Chacoff L, Nebot E, Casanueva JF, Rubio D, Sole M, Mancera JM (2010b) Biomarker responses in Solea senegalensis exposed to sodium hypochlorite used as antifouling. Chemosphere 78:885-893

Loring MD, Thomson EE, Naumann EA (2020) Whole-brain interactions underlying zebrafish behaviour. Cur Opinion Neurobiol 65:88-99

Macedo LPR, Dornelas ASP, Vieira MM, Ferreira JSD, Sarmento RA, Cavallini GS (2020) Effects of lethal and sublethal concentrations of peracetic acid and active chlorine of calcium hypochlorite on Chironomus xanthus. Chemosphere 256

Magalhaes DD, da Cunha RA, dos Santos JAA, Buss DF, Baptista DF (2007) Behavioural response of Zebrafish Danio rerio Hamilton 1822 to sublethal stress by sodium hypochlorite: ecotoxicological assay using an image analysis biomonitoring system. Ecotoxicology $16: 417-422$

Makaras T, Svecevičius G, Kazlauskienė N, Montvydienė D (2018) Rapid detection of sublethal toxicity using locomotor activity of rainbow trout juveniles. Bull Environ Contam Toxicol 100:221-227

Makaras T, Montvydienè D, Kazlauskienė N, Stankevičiūtè M, Raudonytè-Svirbutavičienė E (2020) Juvenile fish responses to sublethal leachate concentrations: comparison of sensitivity of different behavioural endpoints. Enviro Sci Pollut Res 27:4876-4890

Manucat-Tan N, Abdallah RZ, Kaur H, Saviane D, Wilson MR, Wyatt AR (2021) Hypochlorite-induced aggregation of fibrinogen underlies a novel antioxidant role in blood plasma. Redox Biol 40:101847

Melvin SD (2017) Effect of antidepressants on circadian rhythms in fish: insights and implications regarding the design of behavioural toxicity tests. Aquat Toxicol 182:20-30

Nabi G, Wang Y, Hao YJ, Khan S, Wu YF, Li DM (2020): Massive use of disinfectants against COVID-19 poses potential risks to urban wildlife. Environ Res 188

Nimkerdphol K, Nakagawa M (2008) Effect of sodium hypochlorite on zebrafish swimming behaviour estimated by fractal dimension analysis. J Biosci Bioeng 105:486-492

Painter MM, Buerkley MA, Julius ML, Vajda AM, Norris DO, Barber LB, Furlong ET, Schultz MM, Schoenfuss HL (2009) Antidepressants at environmentally relevant concentrations affect predator avoidance behavior of larval fathead minnows (Pimephales Promelas). Environ Toxicol Chem 28:2677-2684

Park KY, Choi SY, Lee SH, Kweon JH, Song JH (2016) Comparison of formation of disinfection by-products by chlorination and ozonation of wastewater effluents and their toxicity to Daphnia magna. Environ Pollut 215:314-321

Pasternak G, Greenman J, Ieropoulos I (2017) Self-powered, autonomous biological oxygen demand biosensor for online water quality monitoring. Sensor Actuat B-Chem 244:815-822

Poopal RK, He Y, Zhao R, Li B, Ramesh M, Ren Z (2021) Organophosphorus-based chemical additives induced behavioural changes in zebrafish (Danio rerio): swimming activity is a sensitive stress indicator. Neurotoxicol Teratol 83:106945

Ren DL, Zhang JL, Yang LQ, Wang XB, Wang ZY, Huang DF, Tian C, Hu B (2018) Circadian genes period $1 \mathrm{~b}$ and period2 differentially regulate inflammatory responses in zebrafish. Fish Shellfish Immun 77:139-146 
Ren Z, Poopal RK, Ramesh M (2021) Synthetic organic chemicals (flame retardants and pesticides) with neurotoxic potential induced behavioural impairment on zebrafish (Danio rerio): a non-invasive approach for neurotoxicology. Environ Sci Pollut Res. https://doi. org/10.1007/s11356-021-13370-2

Rim KT (2021) COVID-19 pandemic and the protection of workers' health from disinfectant chemicals. Toxicol Environ Health Sci 13:1-7

Rivera JM, Gupta S, Ramjee D, El Hayek GY, El Amiri N, Desai AN, Majumder MS (2020) Evaluating interest in off-label use of disinfectants for COVID-19. Lancet Digit Health 2:E564-E566

Senthil Rathi B, Senthil Kumar P, Show PL (2021) A review on effective removal of emerging contaminants from aquatic systems: current trends and scope for further research. J Hazard Mater

Shi WJ, Jiang YX, Ma DD, Huang GY, Xie LT, Chen HX, Huang MZ, Ying GG (2019) Dydrogesterone affects the transcription of genes in visual cycle and circadian rhythm network in the eye of zebrafish. Ecotox Environ Safe 183

Subpiramaniyam S (2021) Outdoor disinfectant sprays for the prevention of COVID-19: are they safe for the environment. Sci Total Environ 759:144289

Ton SS, Chang SH, Hsu LY, Wang MH, Wang KS (2012) Evaluation of acute toxicity and teratogenic effects of disinfectants by Daphnia magna embryo assay. Environ Pollut 168:54-61

Tudela JA, Lopez-Galvez F, Allende A, Hernandez N, Andujar S, Marin A, Garrido Y, Gil MI (2019) Operational limits of sodium hypochlorite for different fresh produce wash water based on microbial inactivation and disinfection by-products (DBPs). Food Control 104:300-307

Ujimine S, Tone S, Saito M, Yamada S (2017) Intracellular morphological changes in Staphylococcus aureus induced by treatment with sodium hypochlorite. Med Mol Morphol 50:178-184

US-EPA (2021): List N Tool: COVID-19 disinfectants., https://cfpub. epa.gov/giwiz/disinfectants/index.cfm. U.S. Environmental Protection Agency, Washington, DC

United States Environmental Protection Agency (US-EPA) 1967https://www.epa.gov/sites/production/files/2015-09/documents/ pr67-5_0.pdf

Wang J, Shen J, Ye D, Yan X, Zhang YJ, Yang WJ, Li XW, Wang JQ, Zhang LB, Pan LJ (2020): Disinfection technology of hospital wastes and wastewater: suggestions for disinfection strategy during coronavirus Disease 2019 (COVID-19) pandemic in China. Environ Pollut 262
World Health Organization, (WHO), 2020. Cleaning and disinfection of environmental surfaces in the context of COVID-19: interim guidance. 15 May 2020. WHO/2019-nCoV/Disinfection/2020.1 (Download link :apps.who.int/iris/bitstream/handle/10665/ 332096/WHO-2019-nCoV-Disinfection-2020.1eng.pdf?seque nce $=1 \&$ is Allowed $=y$ )

Xia CL, Chon TS, Liu YD, Chi J, Lee J (2016) Posture tracking of multiple individual fish for behavioural monitoring with visual sensors. Ecol Inform 36:190-198

Xie HW, Hao HS, Xu N, Liang XX, Gao DX, Xu YR, Gao Y, Tao HC, Wong MH (2019) Pharmaceuticals and personal care products in water, sediments, aquatic organisms, and fish feeds in the Pearl River Delta: occurrence, distribution, potential sources, and health risk assessment. Sci Total Environ 659:230-239

Yang MY, Ren BG, Qiao LL, Ren BX, Hu YY, Zhao RB, Ren ZM, Du J (2018) Behaviour responses of zebrafish (Danio rerio) to aquatic environmental stresses in the characteristic of circadian rhythms. Chemosphere 210:129-138

Yang Y, Dong FS, Liu XG, Xu J, Wu XH, Zheng YQ (2019) Dysregulation of circadian rhythm in zebrafish (Danio rerio) by thifluzamide: involvement of positive and negative regulators. Chemosphere 235:280-287

Yun S, Yoon SY, Hong EJ, Giri SS, Kim SG, Kim SW, Han SJ, Kwon J, Oh WT, Lee SB, Park SC (2020) Effect of plasma-activated water, used as a disinfectant, on the hatch rate of dormant cysts of the Artemia salina. Aquaculture 523

Zhang Y, Ma J, Zhou SY, Ma F (2015) Concentration-dependent toxicity effect of SDBS on swimming behaviour of freshwater fishes. Environ Toxicol Phar 40:77-85

Zhao RB, Hu YY, Li B, Chen M, Ren ZM (2020) Potential effects of internal physio-ecological changes on the online biomonitoring of water quality: the behaviour responses with circadian rhythms of zebrafish (Danio rerio) to different chemicals. Chemosphere 239

Zhao YB, Zhang K, Fent K (2018) Regulation of zebrafish (Danio rerio) locomotor behaviour and circadian rhythm network by environmental steroid hormones. Environ Pollut 232:422-429

Zheng X, Zhang K, Zhao YB, Fent K (2021) Environmental chemicals affect circadian rhythms: an underexplored effect influencing health and fitness in animals and humans. Environ Int 149:106159

Publisher's note Springer Nature remains neutral with regard to jurisdictional claims in published maps and institutional affiliations.

\title{
Authors and Affiliations
}

\author{
Zongming $\operatorname{Ren}^{1} \cdot$ Yaxin $\mathrm{Yu}^{1} \cdot$ Mathan Ramesh ${ }^{2} \cdot{\text { Bin } \mathrm{Li}^{1} \cdot \text { Rama-Krishnan Poopal }}^{1}$ (]) \\ 1 Institute of Environment and Ecology, Shandong Normal \\ University, Jinan 250358, China \\ 2 Unit of Toxicology, Department of Zoology, Bharathiar \\ University, Coimbatore 641046, TamilNadu, India
}

